\title{
BMJ Open Spatial inequalities in life expectancy within postindustrial regions of Europe: a cross-sectional observational study
}

\author{
Martin Taulbut, ${ }^{1}$ David Walsh, ${ }^{2}$ Gerry McCartney, ${ }^{1}$ Sophie Parcell, ${ }^{2}$ \\ Anja Hartmann, ${ }^{3}$ Gilles Poirier, ${ }^{4}$ Dana Strniskova, ${ }^{5}$ Phil Hanlon ${ }^{6}$
}

To cite: Taulbut M, Walsh D, McCartney G, et al. Spatial inequalities in life expectancy within postindustrial regions of Europe: a cross-sectional observational study. BMJ Open 2014;4:e004711. doi:10.1136/bmjopen-2013004711

- Prepublication history and additional material is available. To view please visit the journal (http://dx.doi.org/ 10.1136/bmjopen-2013004711).

Received 18 December 2013 Revised 6 May 2014 Accepted 14 May 2014

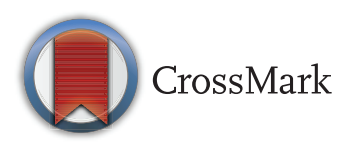

${ }^{1} \mathrm{NHS}$ Health Scotland, Glasgow, UK

${ }^{2}$ Glasgow Centre for Population Health, Glasgow, UK

${ }^{3}$ Ruhr-Universität Bochum, Bochum, Germany ${ }^{4}$ Observatoire Régional de la Santé (ORS), Nord-Pas-deCalais, Loos, France

${ }^{5}$ Regional Public Health Authority of the Olomouc Region of the Czech

Republic, Olomouc, Czech Republic

${ }^{6}$ University of Glasgow, Glasgow, UK

Correspondence to Dr Martin Taulbut; martintaulbut@nhs.net

\section{ABSTRACT}

Objectives: To compare spatial inequalities in life expectancy (LE) in West Central Scotland (WCS) with nine other postindustrial European regions.

Design: A cross-sectional observational study.

Setting: WCS and nine other postindustrial regions across Europe.

Participants: Data for WCS and nine other comparably deindustrialised European regions were analysed. Male and female LEs at birth were obtained or calculated for the mid-2000s for 160 districts within selected regions. Districts were stratified into two groups: small (populations of between 141000 and 185000 people) and large (populations between 224000 and 352000 ). The range and IQR in LE were used to describe within-region disparities.

Results: In small districts, the male LE range was widest in WCS and Merseyside, while the IQR was widest in WCS and Northern Ireland. For women, the LE range was widest in WCS, though the IQR was widest in Northern Ireland and Merseyside. In large districts, the range and IQR in LE was widest in WCS and Wallonia for both sexes.

Conclusions: Subregional spatial inequalities in LE in WCS are wide compared with other postindustrial mainland European regions, especially for men. Future research could explore the contribution of economic, social and political factors in reducing these inequalities.

\section{INTRODUCTION}

Reducing inequalities in health has been identified as a priority by governments across Europe. ${ }^{1}{ }^{2}$ While inequalities in health are often described using individual characteristics (eg, socioeconomic class), there is also considerable interest in spatial disparities in health, ${ }^{3} 4$ despite a lack of research found by Tyner. $^{5}$ All countries exhibit subnational variation in mortality and life expectancy (LE) ${ }^{6-8}$ The pattern is observed for countries as diverse as France, ${ }^{9}$ Sweden, ${ }^{10}$ Australia ${ }^{11}$ and Poland. ${ }^{12}$ Almost universally, the geographical gap in these health outcomes is wider for

\section{Strengths and limitations of this study}

- This is an extensive international comparison of contemporary, within-region disparities in life expectancy. It compares 100 small districts and 60 large districts across 10 European regions.

- Ecological bias was mitigated by selecting regions with a similar history of deindustrialisation and comparing districts with similar-sized populations.

- While the approach taken here partly addressed the scale issue associated with the 'modifiable area unit problem', it was unable to resolve the zoning issue.

- The study was unable to say whether more heterogeneous populations or higher levels of social segregation were driving these differences, though the limited evidence we have does not support this view.

- The analyses are restricted to one period during the mid-to-late 2000s.

- The approach was restricted to describing spatial differences in life expectancy-we cannot draw any conclusions on within-region inequalities by socioeconomic status, rurality or ethnicity.

men than women. ${ }^{13}$ There are some observed differences in within-country dispersion in LE, with the spatial gap being more pronounced for some nations (eg, $\mathrm{USA}^{14}$ and $\mathrm{UK}^{15}$ ) than others (eg, Germany ${ }^{16}$ and Poland ${ }^{12}$ ). Regional inequalities in mortality between English regions, for instance, have been found to be severe and persistent over a 40-year period. ${ }^{17}$ Differences are also observed in whether spatial inequality in mortality has been narrowing, static or increasing over time. ${ }^{13}{ }^{18}$ Although the findings are dependent on the size of geographies selected for analysis, ${ }^{19}$ there is evidence that inequalities between and within English regions have increased over time. ${ }^{17} 20$

Deindustrialisation has been proposed as a mechanism to partly explain these spatial inequalities. Across Europe, there is a clear 
overlap between former coal mining and industrial areas and districts and regions with the poorest health. ${ }^{72}$ Riva and Curtis ${ }^{22}$ found that areas in England with persistently low or deteriorating employment rates (relative to the national average), often located in ex-industrial regions, had the highest rates of mortality and physical morbidity, even after adjusting for migration and individual characteristics of residents. A number of mechanisms (eg, greater poverty, loss of purpose and status and higher levels of substance misuse) provide plausible links between economic dislocation and health outcomes. ${ }^{23} 24$

Making spatial comparisons of health within and between geographies is subject to a number of difficulties. Comparing geographies that have been 'clustered' according to some shared characteristics (such as a similar economic and social history) can partly adjust for this and produce more meaningful results. ${ }^{25}$ Geographical comparisons are more valid when the spatial units being compared are of a similar population size and where there is less social diversity within them, since the differences between areas will depend on the degree to which the geographical units of analysis are internally diverse or homogeneous. Units of analysis with larger population sizes or more heterogeneity in their composition are less likely to display differences between areas because of the averaging effect of this greater internal diversity. ${ }^{19}{ }^{26}$ Failing to take this into account may result in misleading comparisons.

The present study approaches this issue from a Scottish perspective. Scotland's position as the 'sick man' of Europe-characterised by a slower rate of improvement in LE compared with other West European nations since the 1950 s, and a consequent relative deterioration in its international position-has been discussed elsewhere. ${ }^{27} 28$ Furthermore, the within-region spatial gap in mortality was greater in Scotland than any other region of Britain. ${ }^{29}$ A similar 'faltering' in the pace of improvement in mortality and LE has also been noted for West Central Scotland (WCS), the region of Scotland most affected by deindustrialisation in recent decades, relative to other postindustrial regions. ${ }^{30}$ Postindustrial regions are extremely important in epidemiological terms as they tend to exhibit the highest rates of mortality in their parent countries. ${ }^{31} 32$ A recent study also suggested that WCS was more spatially divided in terms of mortality than other comparable European postindustrial regions, though the authors did not pursue this question in depth. ${ }^{31}$ This paper explores this question in a systematic way, to investigate whether spatial disparities in mortality within WCS are large compared with other European regions, taking industrial heritage and differences in population sizes of subregions into account.

\section{METHODS}

This study was informed by the authors' involvement in a larger project which aimed to contribute to an understanding of the poor health observed in one postindustrial region, WCS, in the context of other comparable European regions. WCS is a region of 2.1 million people, centred on the City of Glasgow. Nine other regions, highlighted in other recent epidemiological analyses, ${ }^{30} 32$ were selected for comparison with WCS. The regions were chosen through consultation with experts on European history on the basis of their shared historic economic dependence on industries such as coal, steel, shipbuilding and textiles, alongside analysis of their subsequent loss of industrial employment over the past 30-40 years. ${ }^{30}$

Table 1 presents summary information on the list of regions selected. Selecting a range of regions from across East and West Europe allowed contrasts to be made between WCS and European areas with different social and political contexts. The inclusion of UK regions meant that WCS could be compared with areas subject to the same set of socioeconomic policies over the past 30-40 years.

Male and female LEs at birth were obtained from relevant statistical agencies (or where appropriate calculated) for the mid-2000s, for 160 districts within the 10 selected regions. Ideally, the years of the data collected would be of identical time frame and size. It was not possible or practical to do so here, because of variation between countries in terms of availability of the required small-area statistics data. All life tables were constructed in the same way, using all deaths within each district and the resident population of each district. The sources of the LE data for each region are given in table S2 (web only table).

In order to reduce the risk of bias due to differing subregional population sizes (the scale problem), we stratified the regions into two. Five regions (Swansea and South Wales Coalfields, Northern Ireland, Nord-Pas-de-Calais, Silesia and Merseyside) had subregional (or district) populations of between 141000 and 185000 people. These areas were compared with similarly sized geographies in WCS Community Health Partnership areas (CHPs). Three regions (the Ruhr, Saxony and Wallonia) had LE data calculated across 45 'large' districts of population size ranging from 224000 and 352 000: these were compared with similarly sized WCS Nomenclature of Units for Territorial Statistics (NUTS) 3 areas. Data for Northern Moravia and WCS were available for both strata. For four regions (Northern Ireland, Wallonia, Silesia and Nord-Pas-de-Calais), it was necessary to create pseudodistricts to ensure a more even distribution of population across districts. This process took into account contiguous boundaries and, where possible, the character of districts. LE at birth was then calculated for these new areas using the Chiang ${ }^{33}$ method (II), using population and mortality data obtained from the relevant national statistical agencies.

${ }^{\mathrm{i}}$ There were $15 \mathrm{CHP}$ areas in WCS prior to April 2010, when the five Glasgow CHPs were merged into three. 
Table 1 Postindustrial regions used in the study, by location, characteristics and population of districts

\begin{tabular}{|c|c|c|c|c|c|}
\hline Region name & $\begin{array}{l}\text { Nation } \\
\text { state }\end{array}$ & $\begin{array}{l}\text { Number } \\
\text { of districts }\end{array}$ & $\begin{array}{l}\text { Mean population } \\
\text { size of districts }\end{array}$ & $\begin{array}{l}\text { Principal historical } \\
\text { industries }\end{array}$ & $\begin{array}{l}\text { Total industrial } \\
\text { employment loss }\end{array}$ \\
\hline West Central Scotland & UK & $15 \dagger(7) \ddagger$ & $\begin{array}{l}141268 \dagger \\
(302 \text { 084)‡ }\end{array}$ & $\begin{array}{l}\text { Shipbuilding and support } \\
\text { industries (iron, coal, } \\
\text { engineering) }\end{array}$ & $-62 \%(1971-2005)$ \\
\hline Northern Ireland & UK & 12 & 147900 & $\begin{array}{l}\text { Shipbuilding, textiles, } \\
\text { manufacturing }\end{array}$ & $-20 \%(1971-2005)$ \\
\hline Merseyside & UK & 9 & 149532 & $\begin{array}{l}\text { Shipping, docks, manufacturing } \\
\text { (eg, cement), engineering }\end{array}$ & $-63 \%(1971-2005)$ \\
\hline $\begin{array}{l}\text { Swansea and South } \\
\text { Wales Coalfields }\end{array}$ & UK & 7 & 160486 & Coal & $-51 \%(1971-2005)$ \\
\hline Nord-Pas-de-Calais & France & 25 & 160746 & Coal, textiles, steel & $-43 \%(1970-2005)$ \\
\hline Wallonia & Belgium & 11 & 309542 & Mining, metal working, textiles & $-39 \%(1970-2005)$ \\
\hline The Ruhr & Germany & 15 & 351912 & Coal, iron, steel & $-54 \%(1970-2005)$ \\
\hline Saxony & Germany & 19 & 224934 & $\begin{array}{l}\text { Steel, construction, } \\
\text { engineering, textiles }\end{array}$ & $-47 \%(1991-2005)$ \\
\hline Northern Moravia & $\begin{array}{l}\text { Czech } \\
\text { Republic }\end{array}$ & $11 \S$ & 185099 & Coal, steel & $-19 \%(1993-2005)$ \\
\hline Silesiaף & Poland & 29 & 159858 & Coal, steel, automobiles, zinc & $-55 \%(1980-2005)$ \\
\hline
\end{tabular}

*Percentage decrease in the number of industrial jobs in each region over the time period shown in parentheses.

For Silesia, change is shown for the Katowice subregion.

†Community health partnerships.

‡Nomenclature of Units for Territorial Statistics (NUTS) 3.

$\S J$ Jesenik district included in small district comparisons only.

ๆKnown as the Slaskie region in Poland.

Within regions, we then ranked the subregional (district) populations by their LE separately for men and women and separately for the large and small subregional populations. We then created line graphs for each strata of regions to show the size and distribution of subregional populations and their corresponding LEs. Taking each region separately, we then calculated the range in LE and IQRs, accounting for the population sizes in each subregional district, to describe the withinregional disparities.

\section{RESULTS}

Regions with small district data (populations between 141000 and 185000 )

The districts with the highest male LEs ( $>77$ years at birth) were in the rural districts in Northern Ireland, plus the more affluent WCS districts of East Renfrewshire and East Dunbartonshire. The lowest male LEs ( $<70$ years at birth) were in Silesia and in areas of WCS (North and East Glasgow). The districts with the highest levels of female LE ( $>82.5$ years at birth) were all located in Nord-Pas-de Calais, while the districts with the lowest levels of female LE ( $<78$ years at birth) were in WCS (all five Glasgow districts), Merseyside (City and North Liverpool) and parts of the Silesia region (Ruda Slaska-Swietochlowice and Chorzow-Siemianowice Slaskie).

Within regions, the range in male LE was widest for WCS (8.6 years) and Merseyside ( 5.9 years) and narrowest in Swansea and the South Wales Coalfields (1.6 years) and Northern Moravia (2.7 years). The $I Q R$ in LE for men was widest in WCS and Northern Ireland
(2.7 and 2.6 years, respectively), followed by Silesia (2.2 years), and was much less pronounced in the other regions. For women, WCS had the widest range in LE (6.5 years) and Northern Moravia the narrowest (1.6 years). The range of LEs observed for Merseyside districts was also high (5.9). The $I Q R$ in female LE was highest in Northern Ireland (2 years) and Merseyside (1.9 years) and lowest in Northern Moravia (figure 1 ).

\section{Regions with large district data (populations between 224000 and 352000 )}

The highest male LEs were found in Saxony, Wallonia and the Ruhr, while the lowest were observed in WCS (Glasgow), Wallonia (Mons) and in Northern Moravia. For women, districts with the highest LE were located in Wallonia and Saxony, while the districts with the lowest LE were found within WCS and Northern Moravia.

Within regions, the range in male LE across 'large' districts was widest for WCS (5.3 years), followed by Wallonia ( 4.8 years), with the Ruhr Valley, Saxony and Northern Moravia less polarised. The IQR in LE was much wider in WCS (3.9 years) than in all other regions. For women, the pattern was similar, with the widest range in LE observed for WCS (3.5 years) and Wallonia (2.5 years), with much less disparity evident in the German and Czech regions (figure 2).

\section{DISCUSSION}

Similarly deindustrialised regions in Europe, which share similar economic, social and health problems, ${ }^{30} 32$ display different patterns in spatial inequalities in LE. In 


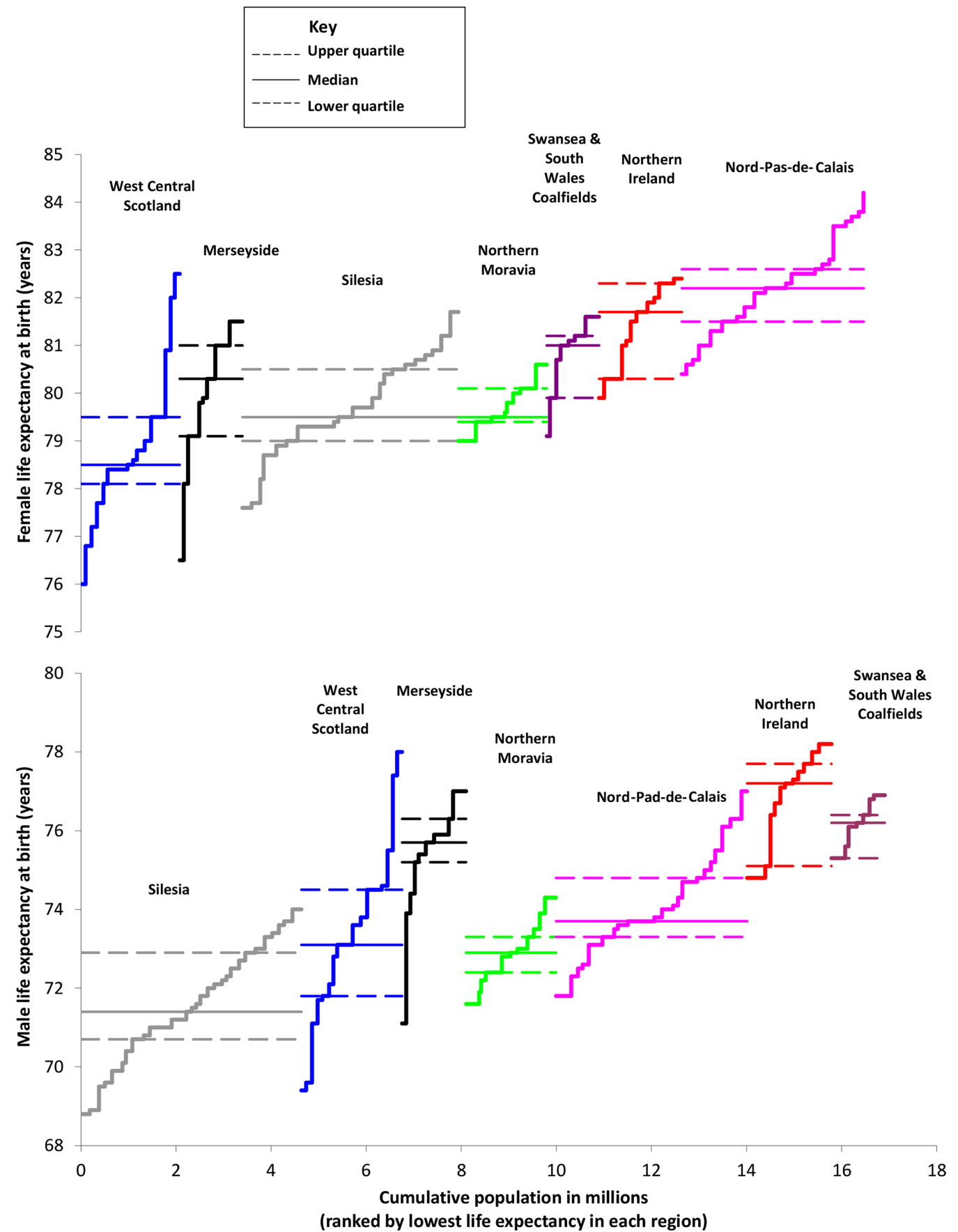

Figure 1 IQR of life expectancy for small districts within seven postindustrial European regions, by gender, mid-to-late 2000s.

particular, two UK regions (WCS and Merseyside) have much larger intraregional differences in LE for men and women than the other regions, with WCS having the largest differences. In contrast, there are relatively narrow spatial inequalities in LE in Northern Moravia, the Ruhr and Swansea and South Wales Coalfields.

The present study has four important strengths. First, it provides an original comparison of contemporary, international and within-region disparities in LE. Second, its geographical coverage is extensive: more than 100 small districts and 60 large districts, spanning 10 regions across Western and Eastern Europe. Third, it uses a straightforward metric of health outcomes (LE at birth) that is readily understood. Finally, by attempting to ensure that the areas are of a similar size and have a common experience of industrial development and subsequent deindustrialisation, the potential bias arising from comparisons of differently sized populations and the heterogeneity within regions is reduced.

The study also has a number of limitations. A key challenge in any study of this kind is the 'modifiable area unit problem' (MAUP). As discussed by Openshaw, ${ }^{34}$ the spatial units that can be used to describe individuallevel data are usually highly modifiable and their 

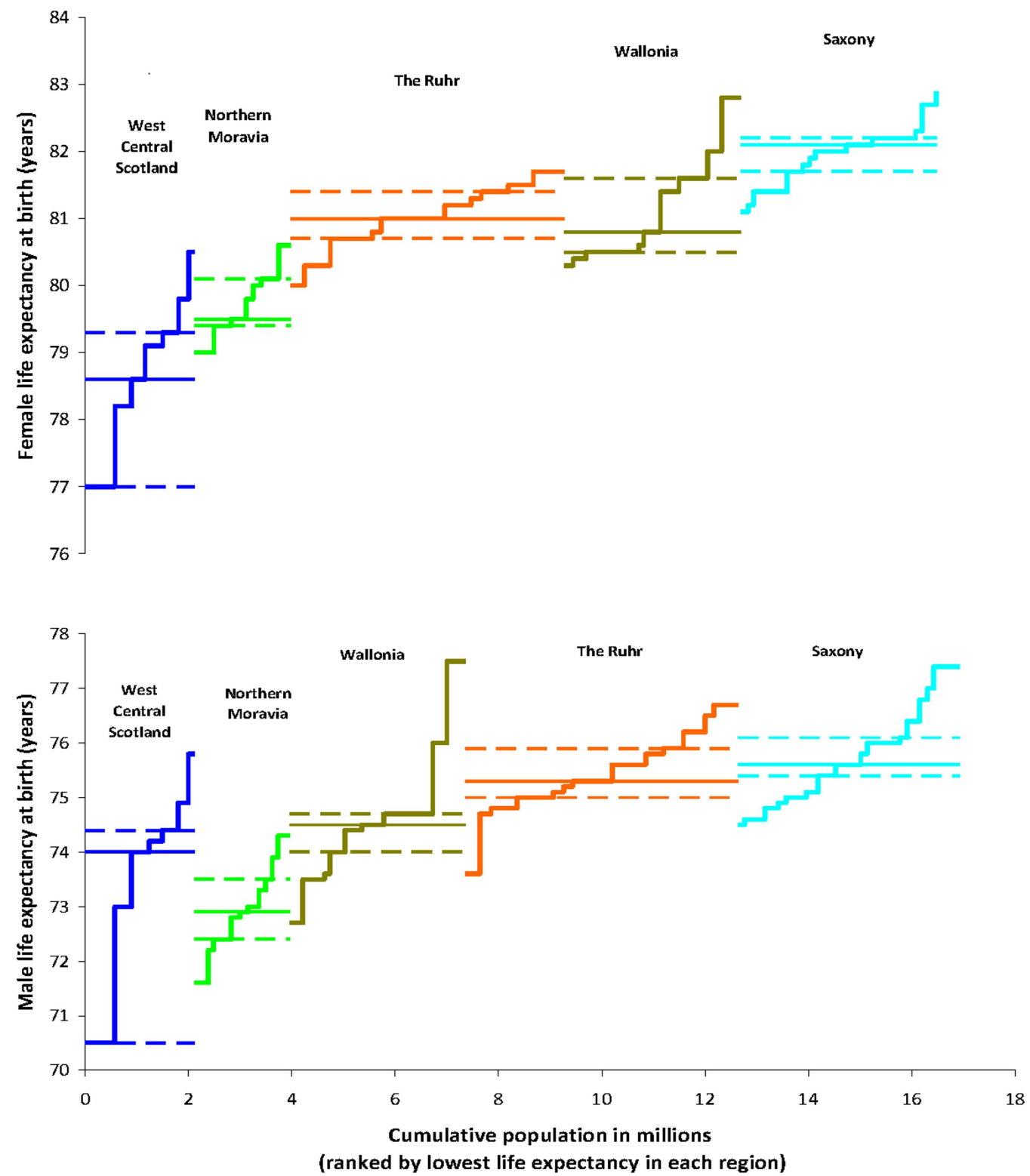

Figure 2 IQR of life expectancy for large districts within five postindustrial European regions, by gender, mid-to-late 2000s.

boundaries are often decided on an arbitrary basis. There are a large number of different spatial units that could be used to describe the same data, often producing quite different conclusions. There are two components of the MAUP. First, there is a scale problem, with different results being produced depending on the number of spatial units used in analysis (eg, for census tracts, districts, regions). Second, there is a grouping or zoning problem, reflecting different choices about how very small areas are joined together to create areas of a similar size. In this study, the scale problem has been partly addressed by making comparisons of subregional inequalities at two different geographical levels. The similar findings (of greater spatial inequalities in WCS) for both scales can give more confidence that the approach adopted is reasonable. However, the zoning problem remains difficult to resolve without access to individual-level data coded to geographic areas, which are currently not available. It is important to note that the findings may not apply beyond the selection of postindustrial regions shown here. For example, Hoffman et $a l^{35}$ who analysed neighbourhood-level differences in mortality for 15 large European large cities, found that inequalities were wider for women than for men, and there was no evidence that within-area inequalities varied between cities.

The methods used to compare spatial inequalities (IQR) could also be criticised as not ideal. Other studies $^{36}$ have used the slope index of inequality and relative index of inequality to estimate spatial inequalities in mortality. ${ }^{37}$ This would undoubtedly allow for more robust analyses. However, to allow these indices to be constructed would require robust, internationally comparable measures for ranking all the districts by 
socioeconomic status. Data limitations make this a difficult task. Europe-wide indicators of material and income deprivation are unavailable for small-area geographies. A prototype European Socio-economic Classification ${ }^{38}$ has been developed, but comparable small-area data (from national censuses) for all areas are not yet available. Limited measures of housing tenure and car ownership are available, though these may also reflect different cultural patterns between countries rather than deprivation per se (eg, the different role that renting plays in the German housing market ${ }^{39}$ ). Some studies have also questioned whether car ownership is a good indicator of deprivation. ${ }^{40}{ }^{41}$ Measures of unemployment might also be challenged as not fully comparable either, due to the large-scale diversion of working-age adults into economic inactivity (eg, disability benefits) during the 1990s across many European countries. ${ }^{42}$ Exploring options to overcome these methodological challenges might be a useful avenue for future research.

Data restrictions mean we were unable to explore systematically the degree of social segregation or migration within each region. Spatial inequalities observed could simply reflect greater population heterogeneity between districts within each region. However, evidence comparing WCS with the Ruhr and Nord-Pas-de-Calais does not support this hypothesis. ${ }^{43} 44$ Nor can we say how spatial inequalities in LE changed within these regions over time, since the analysis is also confined to a single time period. Lack of individual-level data and common markers of socioeconomic status meant that this study was also confined to a focus on spatial differences in LE. If data had been available, analysis by inequalities by socioeconomic status or other characteristics (eg, rurality and ethnicity) may have led to different conclusions. For example, in Northern Moravia, the gap in male LE between districts was approximately 5 years, ${ }^{45}$ but the gap in LE between the highest and least-educated men has been enumerated at 16.5 years. ${ }^{46}$

The more pronounced spatial inequalities in LE in three of the four UK regions, especially WCS, are notable. What factors might help account for this? As reported elsewhere, despite the relatively high levels of mean prosperity and lower unemployment, WCS and the other British regions have higher levels of relative poverty, income inequality and single person and lone parent households compared with postindustrial areas of mainland Europe. ${ }^{32}$ There is also a more mixed pattern on some other indicators (eg, social capital and educational attainment). ${ }^{32}$ It would be appropriate to consider the sociopolitical context to this. Others have contrasted the UK "path destructive' road to deindustrialisation, characterised by the growth of a low-wage service sector and reduced social protection, with alternative strategies pursued in mainland Europe. ${ }^{24}{ }^{47}$ It has been argued that a more rapid adoption of neoliberal politics by local government in WCS alongside greater vulnerability to the deleterious impacts of associated economic policies might provide some basis for explaining the findings for WCS. ${ }^{24} 48$
There may be differences between regions in the homogeneity of the populations, and the degree to which there is social segregation. It is possible that the greater disparities observed in WCS could be due to greater social segregation rather than larger socioeconomic inequalities (although the likelihood of this is reduced by the same finding being observed at two different sizes of subregional districts). The limited analyses available (comparing spatial segregation in Nord-Pasde-Calais and Merseyside with WCS) suggests that this cannot provide a wholly adequate explanation for the results shown here. ${ }^{31}$ Nor is it clear that stronger withinregion migration (from the unhealthiest to the healthiest districts) in WCS can explain these differences. One comparative study of WCS and the Ruhr (1995-2008) suggests that this pattern took place in both regions and, if anything, seemed to be slightly stronger in the Ruhr than in WCS. ${ }^{43}$ This view is supported by Popham et $a l^{49}$ who argued that selective out-migration is not the only or most important reason for the wide levels of health inequality seen in the region.

Differences in overall population change might provide a partial explanation. Recent long-run analysis of commune-level data for France by Ghosn et a $\tilde{p}^{0}$ found that population growth was associated with decreases in relative mortality. Between 1982 and 2005, while most of the regions included in our study saw little change in their population, WCS saw a marked decline; while Saxony saw an even larger loss of its population over a shorter time frame. ${ }^{30}$ This might explain why inequalities in LE were wider in the Scottish region, but the much narrower inequalities in Saxony suggest that this may not be the whole story.

It may be that in other countries, 'protective' factors such as lower levels of income inequality (Northern Moravia), ${ }^{51}$ higher levels of social capital (The Ruhr) ${ }^{43}$ or fewer lone parent or single person households (Nord-Pas-de-Calais) ${ }^{44}$ or a more managed deindustrialisation process, which included active labour market policies and re-employment in new industrial sectors, ${ }^{24}$ might have partly mitigated against the health-damaging effects of deindustrialisation, reducing the extent of spatial inequalities in health. However, as yet unexplained region-specific factors are also likely to play a role. Within the UK, Swansea and South Wales have relatively narrow spatial inequalities in health and WCS has some of the widest. In the former case, this may partly reflect the more homogeneous social mix across ex-mining areas/ villages, compared with more metropolitan areas.

Difference in lifestyle factors (ie, worse health behaviours in WCS) could also play a role. This argument is more plausible for alcohol, since levels of consumption and alcohol-related harm are high in WCS for both genders compared with the other regions. ${ }^{32}$ For smoking and diet, matters are less clear. Female smoking rates are higher in WCS compared with most regions but male smoking rates are similar across all regions. ${ }^{32}$ Dietary indicators suggest that WCS compares 
poorly with Nord-Pas-de-Calais but is very similar to Merseyside and Northern Ireland. ${ }^{31}$ That said, any explanation based on health behaviours alone would be insufficient, as the underlying causes of these health behaviours would remain unexplained.

Finally, environmental factors, such as air pollution and climate, have also been proposed as possible explanations for health inequalities. Could these factors explain the results? Richardson et $a l^{52}$ found that while exposure to particulate air pollution (PM10), and risk of some causes of mortality, was higher in low-income European regions, their mapping also revealed the concentration of the worst areas of pollution in East European regions (including Silesia and Northern Moravia). Although vitamin D deficiency (linked to lower levels of sunlight) may be higher in WCS than some other regions, the detrimental impacts on health are likely to be observed among older people. ${ }^{53}$ Decomposition of the excess mortality observed in WCS compared with European regions shows it to be greatest among the working-age population, especially young men and middle-aged women. ${ }^{30}$ It therefore seems less plausible that the observed difference in spatial inequalities can be attributed to environmental factors.

\section{CONCLUSIONS}

Subregional spatial inequalities in LE in WCS are wide compared with other postindustrial European regions, even after accounting for differences in the population size of the subregional districts. These spatial inequalities are particularly profound for men. By contrast, within-region spatial inequalities in LE were relatively low in the German and Czech regions. These data generally show similar patterns to that for inequalities by individual educational attainment for the parent countries. ${ }^{54}$ Outside the UK, wider determinants of health (such as income distribution, positive social capital and family networks) may have acted to protect health in postindustrial regions. Future research could explore the contribution of these wider determinants of health to reducing spatial inequalities in mortality, especially in WCS.

Acknowledgements This project would not have been possible without the cooperation and assistance of a number of individuals and organisations. In particular, the authors would like to thank the following for all their help in providing the required data: National Records for Scotland (NRS), formerly General Register Office for Scotland; Northern Ireland Statistics and Research Agency; Office for National Statistics and Public Health Intelligence Team, Information \& Intelligence Services, Liverpool Primary Care Trust; Office for National Statistics (Vital Statistics); INSEE and Centre d'épidémiologie sur les causes médicales de décès (CepiDc; Original data provided by Observatoire Régional de la Santé (ORS), NPdC); SPMA (https://www.wiv-isp.be/epidemio/ spma), Public Health and Surveillance, Scientific Institute of Public Health, Brussels, Belgium; NRW Institute of Health and Work (LIGA.NRW); Statistisches Landesamt des Freistaates Sachsen; Czech Statistical Office; Central Statistical Office of Poland-Local Data Bank. The authors would like to thank the reviewers, Peter Congdon and Paul Norman, for their useful comments on an earlier draft of this paper.
Contributors GM and DW conceived the idea for the paper and designed the study. All authors were involved in the acquisition of data, its analysis and interpretation. All authors contributed to the drafting and revision of the paper.

Funding This research received no specific grant from any funding agency in the public, commercial or not-for-profit sectors.

\section{Competing interests None.}

Provenance and peer review Not commissioned; externally peer reviewed.

Data sharing statement The data used to create figures 1 and 2 are available on request from the corresponding author.

Open Access This is an Open Access article distributed in accordance with the terms of the Creative Commons Attribution (CC BY 3.0) license, which permits others to distribute, remix, adapt and build upon this work, for commercial use, provided the original work is properly cited. See: http:// creativecommons.org/licenses/by/3.0/

\section{REFERENCES}

1. Scottish Government. Equally well: report of the Ministerial Task Force on health inequalities. Edinburgh: The Scottish Government, 2008.

2. Mackenbach JP. Health inequalities: Europe in profile. Rotterdam: Erasmus MC, 2006.

3. Shaw M, Thomas B, Davey Smith G, et al. The Grim Reaper's road map: an atlas of mortality in Britain. Bristol: The Policy Press, 2008.

4. Bonneux LG, Huisman CC, de Beer JA. Mortality in 272 European regions, 2002-2004. An update. Eur J Epidemiol 2010;25:77-85.

5. Tyner JA. Population geography II: mortality, premature death, and the ordering of life. Prog Hum Geogr. 1-14. DOI:10.1177/ 0309132514527037

6. Ezzati M, Friedman AB, Kulkarni SC, et al. The reversal of fortunes: trends in county mortality and cross-county mortality disparities in the United States. PLoS Med 2008;5:557-68.

7. European Commission. Health statistics-atlas on mortality in the European Union. Luxembourg: Office for Official Publications of the European Communities, 2009.

8. Suzuki E, Kashima S, Kawachi I, et al. Social and geographic inequalities in premature adult mortality in Japan: a multilevel observational study from 1970 to 2005. BMJ 2012;2:e000425.

9. Windenberger F, Rican S, Jougla E, et al. Spatiotemporal association between deprivation and mortality: trends in France during the nineties. Eur J Public Health 2012;22:347-53.

10. Statistics Sweden. Demographic reports 2007:1, life expectancy in Sweden 2001-2005. Life expectancy tables for the country and by county. Stockholm: Statistics Sweden, 2007

11. Australian Bureau of Statistics. Feature article-regional mortality. 2002. http://www.abs.gov.au/ausstats/abs@.nsf/featurearticlesbytitle/ 5D0B63A4CED5187DCA256C8C007DF565?OpenDocument (accessed 23 Aug 2012).

12. GUS. Life expectancy tables of Poland 2010. Warsaw: GUS, 2011

13. Vallin J, Mesle F, Valkonen T. Trends in mortality and differential mortality. Strasbourg: Council of Europe, 2001.

14. Murray CJL, Michaud CM, McKenna MT, et al. Patterns of mortality by county and race: 1965-94. Cambridge, MA: Harvard Center for Population and Development Studies, 1998.

15. Office for National Statistics. Life expectancy at birth and at age 65 by local areas in the United Kingdom, 2004-06 to 2008-10. Newport: ONS, 2011.

16. Edenharter G, Haas K, Schober-Halstenberg HJ, et al. Regional life expectancy in Germany: life table analysis for 1997/1999 to 2004/ 2006. Part A: methods and summary of results. 2009. http://www. edenharter-research.de/regle_de/pdf/RegLE_DE_PartA.pdf (accessed 23 Aug 2012).

17. Hacking JM, Muller S, Buchan IE. Trends in mortality from 1965 to 2008 across the English north-south divide: comparative observational study. BMJ 2011;342:d508.

18. Dorling D. Death in Britain: how local mortality rates have changed: 1950s-1990s. York: Joseph Rowntree Foundation, 1997.

19. Jackson AL, Davies CA, Leyland AH. Do differences in the administrative structure of populations confound comparisons of geographic health inequalities? BMC Med Res Methodol 2010;10:74.

20. Rees $\mathrm{P}$, Brown D, Norman $\mathrm{P}$, et al. Are socioeconomic inequalities in mortality decreasing or increasing within some British regions? An observational study, 1990-1998. J Public Health Med 2003;25:208-14. 
21. Riva M, Terashima M, Curtis S, et al. Coalfield health effects: variation in health across former coal field areas in England. Health Place 2011;17:588e97.

22. Riva M, Curtis SE. Long-term local area employment rates as predictors of individual mortality and morbidity: a prospective study in England, spanning more than two decades. J Epidemiol Community Health 2012;66:919-26.

23. Bartley M. Unemployment and ill health: understanding the relationship. J Epidemiol Community Health 1994:48:333e7.

24. Collins C, McCartney G. The impact of neoliberal 'political attack' on health: the case of the 'Scottish Effect'. Int J Health Serv 2011;41:501-13.

25. Application of cluster analysis towards the development of health region peer groups. Statistical Society of Canada, Annual Meeting; June 2003

26. Shaw M, Orford S, Brimblecombe $\mathrm{N}$, et al. Widening inequality in mortality between 160 regions of 15 European countries in the early 1990s. Soc Sci Med 2000;50:1047-58.

27. Whyte B. Scottish mortality in a European context 1950-2000. An analysis of comparative mortality trends. Edinburgh: Information Services, NSS, 2006

28. McCartney G, Walsh D, Whyte B, et al. Has Scotland always been the 'sick man' of Europe? An observational study from 1855 to 2006. Eur J Public Health 2011;22:756-70.

29. Leyland A. Increasing inequalities in premature mortality in Great Britain. J Epidemiol Community Health 2004;58:296-302.

30. Walsh D, Taulbut M, Hanlon P. The aftershock of deindustrialization - trends in mortality in Scotland and other parts of post-industrial Europe. Eur J Public Health 2010;20:58-64.

31. Taulbut M, Walsh D, Parcell S, et al. Health and its determinants in Scotland and other parts of post-industrial Europe: the Aftershock of Deindustrialisation Study phase two. Glasgow: GCPH, 2011.

32. Taulbut M, Walsh D, Parcell S, et al. What can ecological data tell us about reasons for divergence in health status between West Central Scotland and other regions of post-industrial Europe? Public Health 2012;127:153-63. http://dx.doi.org/10.1016/j.puhe.2012.11.007

33. Chiang CL. The life table and mortality analysis. Geneva: World Health Organization, 1978.

34. Openshaw S. The modifiable area unit problem. Norwich: Geo Books, 1984

35. Hoffmann R, Borsboom G, Saez M, et al. Social differences in avoidable mortality between small areas of 15 European cities: an ecological study. Int J Health Geogr 2014;13:8. http://www. ij-healthgeographics.com/content/13/1/8

36. Thomas B, Dorling D, Davey Smith $G$. Inequalities in premature mortality in Britain: observational study from 1921 to 2007. BMJ 2010;341:c3639.

37. Munoz-Arroyo R, Sutton M. Measuring socio-economic inequalities in health: a practical guide. Edinburgh: ScotPHO, 2007.
38. Rose D, Harrison E. The European Socio-economic Classification: a new social class schema for comparative European research. European Societies 2007;9:459-90.

39. Whitehead CME, Scanlon K. Social housing in Europe. In: Whitehead CMEScanlon K. eds. Social housing in Europe.London: LSE, 2007:8-33.

40. Focas C. The four world cities transport study. London: The Stationery Office, 1998.

41. Johnson V, Currie G, Stanley J. Measures of disadvantage: is car ownership a good indicator? Soc Indic Res 2010;97:439-50.

42. OECD. Transforming disability into ability: policies to promote work and income security for disabled people. Paris: OECD, 2003.

43. Parcell S, Hartmann A, Taulbut M, et al. Case study: health and its determinants in West Central Scotland compared to the Ruhr area in Germany. Glasgow: GCPH, 2011.

44. Taulbut M, Poirier G, Walsh D. Case study: health and its determinants in West Central Scotland compared to Nord-Pas-de-Calais in France. Glasgow: GCPH, 2011.

45. CZSO. Life expectancy in districts (LAU 1) in 2005-2009 (data extra regular outputs). http://www.czso.cz/eng/redakce.nsf/i/life_tables (accessed Aug)

46. van Raalte $A A$, Kunst $A E$, Lundberg $O$, et al. The contribution of educational inequalities to lifespan variation. Popul Health Metr 2012;10:3.

47. Birch K, Mykhnenko K. Varieties of neoliberalism? Restructuring in large industrially dependent regions across Western and Eastern Europe. J Econ Geogr 2009;9:355-80.

48. Boyle M, McWilliams C, Rice G. The spatialities of actually existing neoliberalism in Glasgow, 1977 to present. Geografiska Annaler, Series B: Human Geography 2008;90:313-25.

49. Popham F, Boyle PJ, O'Reilly D, et al. Selective internal migration. Does it explain Glasgow's worsening mortality record? Health Place 2011;17:1212-17.

50. Ghosn W, Kassié D, Jougla E, et al. Trends in geographic mortality inequalities and their association with population changes in France 1975-2006. Eur J Public 2013;23:834-40.

51. Walsh D, Strniskova D, Taulbut M. Case study: health and its determinants in West Central Scotland compared to Northern Moravia in the Czech Republic. Glasgow: GCPH, 2011.

52. Richardson EA, Pearce J, Tunstall $\mathrm{H}$, et al. Particulate air pollution and health inequalities: a Europe-wide ecological analysis. Int $J$ Health Geogr 2013;12:34.

53. Rush L, McCartney G, Walsh D, et al. Vitamin D and subsequent all-age and premature mortality: a systematic review. BMC Public Health 2013;13:679.

54. Popham F, Boyle P. Assessing socio-economic inequalities in mortality and other health outcomes at the Scottish national level. Edinburgh: Scottish Collaboration for Public Health Research and Policy, 2011. 